\title{
Adsorption Characteristics of Copper (II) Ions from Aqueous Solution onto Ionic Cross-linked Pva/P(Aam-Nipaam) Core-shell Nanogels
}

\author{
Ali Ali Sarhan, Magda Ali Akl* and Kamal Razaq \\ Chemistry Department, Faculty of Science, Mansoura University, Mansoura, Egypt
}

\begin{abstract}
Core-shell nanogels adsorbent were investigated for copper (II) removal from aqueous solution, consisting of poly(vinyl alcohol) (PVA) core and poly(acrylamide- N-isopropylacrylamide/) p(AAm-NIPAm) shell particles. Various factors affecting the adsorption capacity, such as swelling, $\mathrm{pH}$, time, initial ion concentration, and different metal ions on the metal ion binding capacity for nanogel, was also tested. The selectivity of the nanogels toward the different metal ions tested was $\mathrm{Cu}^{2+}>\mathrm{N}^{2+}>\mathrm{Pb}^{2+}$. The results show that the adsorption of nanogels mainly depends on $\mathrm{pH}$, and the maximum adsorption was obtained at a $\mathrm{pH}$ of 6.0 . The adsorption capacity of $\mathrm{Cu}^{+2}$ was $126 \mathrm{mg} / \mathrm{g}$ obtained under simple and fast experimental conditions, the effect of different mole ratios of $p(A A m-N I P A m)$ shells thickness were synthesized, to determine the maximum metal uptake. The core-shell nanogels were characterized by fourier transform infrared spectroscopy (FTIR), thermogravimetric analysis (TGA) and transmission electron microscope (TEM). It was found that adsorbed $\mathrm{Cu}^{+2}$ ions on PVA/p(AAm-NIPAm) nanogels can be effectively desorbed by acid stripping with $0.1 \mathrm{~mol} / \mathrm{L} \mathrm{HCl}$ resulted in $96 \% \mathrm{Cu}^{+2}$ recovery for the nanogels; this shows the ability of the nanogels to be reused, upon drying between treatments. The nanogels adsorbent can be regenerated after releasing of $\mathrm{Cu}^{+2}$ and reused three times effectively. All the experimental result exhibited good matches with the Freundlich isotherm and followed pseudo-second-order kinetics. The mechanism of adsorption of $\mathrm{Cu}^{+2}$ onto PVA/p(AAm-NIPAm) nanogels is proposed.
\end{abstract}

Keywords: Nanogels adsorbent; Acrylamide; $\mathrm{Cu}^{+2}$; Adsorption behavior

\section{Introduction}

Heavy metals pollution can cause a serious environmental hazard due to its high toxicity and non-biodegradability, which effects on the natural environment and its accumulation in living organisms [1,2]. Heavy metals are generally discharged to the environment via mining activities, fossil fuels, battery manufacture, and automobile emissions [3].

Copper has been detected as a pollutant because of its widespread occurrence and toxic effect upon the environment. It catalyzes the formation of highly reactive oxygen species, which leads to lipid peroxidation and the lack of the reduced form of glutathione which increases the methemoglobin content [4]. Excess of $\mathrm{Cu}^{+2}$ in the human body has been reported to be linked to serious health harms such as cellular or main organ damage and Wilson's disease $[5,6]$. To avoid significant toxic effects on aquatic ecosystems, highly selective and efficient technologies to remove/recover metal ions from natural water is needed. Adsorption considered an attractive method that allows flexibility in design and operation, regeneration of the adsorbent by suitable desorption process, and it is highly effective and more economical $[7,8]$. Hydrogels containing amide, amine, carboxylic acid, hydroxyl, and ammonium groups can bind with metal ions and be good polychelatogens for water purification Applications [9].

The first environmental applications of polymeric adsorbents were investigated by Snowden and Vincent in 1993, who explored the applicability of using poly ( $\mathrm{N}$-isopropylacrylamide) nanoparticles to remove $\mathrm{Pb}^{2+}$ and $\mathrm{Cd}^{2+}[10]$. However, the removal capacity of both heavy metal ions was limited as the ratio of the initiator to NIPAm was kept small in all the synthesis therein. This shortcoming in adsorption capacity was later overcome by synthesizing it together with a second comonomer, acrylamide that contain amide bonds showing good water solubility and strong complexation ability with metal ions. Poly(vinyl alcohol) (PVA) polymer used for a long time in biotechnical and biomedical communities. It is used as a basic material for a variety of biomedical applications because of their inherent non-toxicity, noncarcinogenicity, exhibit good biocompatibility, and desirable physical properties [11]. Investigations have been done on its use in the field of separation processes $[12,13]$. In this article, the PVA is an initial core of $\mathrm{p}$ (AAm-NIPAm) nanogels, and the core was formed in an aqueous acetone solution then crosslinked with epichlorohydrin (EPC). An innovative synthesis method was used to synthesize PVA/p(AAmNIPAm) nanogels in an aqueous system.

The objective of this work is to develop PVA/p(AAm-NIPAm) core-shell hydrogels nanoparticle with different mole ratios of copolymerized (AAm-NIPAm) with respect to the amount of PVA as a potential effective adsorbents to remove $\mathrm{Cu}^{+2}$ from aqueous solution attributing to their following unique properties: (i) PVA core is a hydrophilic macromolecule and readily dissolves in water, so that the dynamic behavior of PVA polymer chain is highly sensitive to the solvent quality in a dilute solution [14], so used as solid carriers afford mechanic strength to enhance the usable life. (ii) pNIPAm hydrogel swollen in water is a typical temperature-sensitive hydrogel that exhibits a volume phase transition (VPT) in response to temperature changes at around $33^{\circ} \mathrm{C}[15]$. However, it has a very low mechanical strength. On the other hand, AAm is a versatile hydrophilic comonomer but its homopolymer does not show a volume phase transition temperature in water [16]. Introduction of AAm component improves the

*Corresponding author: Magda Ali Akl, Chemistry department, Faculty of Science, Mansoura University, Mansoura, Egypt, Tel: 0020502217833; E-mail: magdaakl@yahoo.com

Received August 16, 2015; Accepted November 28, 2015; Published December 08,2015

Citation: Sarhan AA, AkI MA, Razaq K (2015) Adsorption Characteristics of Copper (II) lons from Aqueous Solution onto lonic Cross-linked Pva/P(Aam-Nipaam) Coreshell Nanogels. J Nanomedic Nanotechnol S7:001. doi:10.4172/2157-7439. S7-001

Copyright: (c) 2015 Sarhan AA, et al. This is an open-access article distributed under the terms of the Creative Commons Attribution License, which permits unrestricted use, distribution, and reproduction in any medium, provided the original author and source are credited. 
mechanical strength of pNIPAm hydrogels, so that p(AAm-co-NIPA) hydrogels should have both good mechanical strength and temperature sensitivity. Moreover, the $\mathrm{p}$ (AAm-NIPAm) shells provide much larger specific surface area. (iii) The raw materials are low-cost and the synthetic approach is simple, which make these nanoparticles potential commercializable. (v) PVA/p(AAm-NIPAm) core-shell nanogels are environmental-friendly nanomaterials due to offer biocompatibility. These nanoparticles do not cause environmental pollution during the course of treatment, indicating that PVA/p (AAm-NIPAm) hydrogels nanoparticles can be used as effective and practical polymeric adsorbents.

\section{Experimental}

\section{Materials}

$\mathrm{N}$ - Isopropylacrylamide (NIPAm, Across $99 \%$ purity) was re-crystallized from 1:5 (v:v) toluene and n-hexane mixture; Acrylamide (AAm, purified by rectify, purchased from Acros); PVA (polymerization degree is $1750+50$, purchased from Acros); $\mathrm{N}, \mathrm{N}$-methylene-bisacrylamide (MBA), Epichlorohydrin (ECH; Fluka), ammonium peroxydisulfate (APS) was used without further purification; $\mathrm{CuSO}_{4} .5 \mathrm{H}_{2} \mathrm{O}$ was purchased from VWR International (West Chester, PA). Other reagents were grade and used as received.

\section{Synthesis of PVA/p(AAm-NIPAAm) nanogels}

Core synthesis: $2 \mathrm{wt} \%$ of PVA dissolved in $100 \mathrm{~mL}$ distilled water. A solution of $1.66 \mathrm{~g} \mathrm{NaOH}$ in $3 \mathrm{~mL}$ of water was slowly added till $\mathrm{pH} 12$ via syringe with vigorous stirring. After becoming clear and homogeneous, added $15 \mathrm{~mL}$ of acetone drop wise with stirring for 30 min. The solution was cooled at $10^{\circ} \mathrm{C}$ for $24 \mathrm{~h}$ and it became weak blue, indicating that the long chains of PVA shrank to nanoparticles.

Shell synthesis: The polymerization reaction carried out in a $250 \mathrm{ml}$ four-necked flask, 0.9 mol\% of AAm, $0.1 \mathrm{~mol} \%$ of NIPAm and $300 \mu \mathrm{L}$ of MBA $(0.049 \mathrm{~g} / \mathrm{mL})$ were fully dissolved in $50 \mathrm{ml}$ deionized water and then added drop wise to APS solution $(50 \mu \mathrm{L}$ in $50 \mathrm{~mL}$ deionized water) via the semibatch method at intervals of $2 \mathrm{~h}$ and reaction temperature of $70^{\circ} \mathrm{C}$. The whole reaction lasted for $4 \mathrm{~h}$ under nitrogen atmosphere. Similarly, different (AAm-co-NIPAm) copolymers hydrogel ranging from 0.7:0.3, 0.5:0.5, 0.3:0.7 and 0.1:0.9 (mol:mol\%) respectively were synthesized.

Core-shell crosslinking: Take $50 \mathrm{ml}$ PVA solution as a constant amount, added $1 \mathrm{~mL}$ epichlorohydrin and $50 \mathrm{~mL}$ from synthesized (AAm-co-NIPAm) with different ratios and heat with stirring at $98^{\circ} \mathrm{C}$ for $10 \mathrm{~h}$ in order to obtain core-shell structure under nitrogen atmosphere. The obtained nanogels could be used directly or could be frozen and lyophilized into freeze-dried powder PVA/p(AAmNIPAm), which can be easily predispersed into water forming nanoparticle dispersion.

\section{Characterization}

The chemical structure of the PVA/p(AAm-NIPAm) core-shell nanogels was directly analyzed by a FTIR spectrometer (Nicolet, NEXUS-670). The thermal property of the nanogels was observed by thermogravimetric analysis (TGA) (SDT Q600 V20.5 Build 15) instrument at $20 \mathrm{kV}$. The temperature range was from ambient to $250^{\circ} \mathrm{C}$ with heating rate of $5^{\circ} \mathrm{C} / \mathrm{min}$. Transmission electron microscope (TEM) of colloidal nanogels particle were taken using an H-800 electron microscope (Hitachi, Tokyo, Japan). The sample was prepared by placing a dilute drop of aqueous particles onto the copper grids and allowing it to dry. The $\mathrm{pH}$ of solutions was adjusted with small amounts of $0.1 \mathrm{M}$ hydrochloric acid and sodium hydroxide and determined using a digital pH meter (pHS-4CT, Shanghai Dazhong Analytical Instrument).

Metal analysis by using the Atomic Absorption Spectrophotometer technique followed the direct aspiration into an air-acetylene flame using the atomic absorption (Hewlett- Packard 3510).

\section{Adsorption experiments}

The adsorption experiments of $\mathrm{Cu}^{+2}$ were carried out according to the batch method. The conical flasks containing $0.05 \mathrm{~g}$ adsorbent and $10 \mathrm{~mL} \mathrm{Cu}^{+2}$ solution with the initial $\mathrm{pH}$ value $6.0 \pm 0.1$ were placed on a constant temperature bath oscillator to vibrate at room temperature $\left(25 \pm 1^{\circ} \mathrm{C}\right)$. After a period of time, the PVA/p (AAm-NIPAm) nanogels adsorbent were separated from the solutions and the initial and final metal concentrations were determined by

$$
\text { Adsorption } \%=\left(\frac{C_{i}-C_{e}}{C_{i}}\right) \times 100
$$

Where, $\mathrm{C}_{\mathrm{i}}$ and $\mathrm{C}_{\mathrm{e}}$ are the initial and equilibrium concentration of metal ion $(\mathrm{mg} / \mathrm{L})$ in the solution. The adsorption capacity was calculated by using the mass balance equation for the adsorbent:

$$
q_{e}=\left(\frac{C_{i}-C_{e}}{W}\right) \times v
$$

Where, $\mathrm{q}_{\mathrm{e}}$ is the adsorption capacity $(\mathrm{mg} / \mathrm{g}), \mathrm{V}$ is the volume of metal ion solution (L) and $\mathrm{W}$ is the weight of the adsorbent (g).

Swelling behavior of PVA/p(AAm-NIPAm) nanogels: $0.05 \mathrm{~g}$ of nanogels immersed in a $25 \mathrm{ml}$ deionized water at $25^{\circ} \mathrm{C}$. At specific time intervals the swollen nanogels was taken out, wiped superficially with filter paper to eliminate extra surface water weighed to obtain the weight $\mathrm{w}$ at time $\mathrm{t}$. The procedure was repeated until no significant change of weight was detected. The swelling $\%$ can be calculated by:

$$
\text { Swelling } \%=\left(\frac{W_{s}-W_{d}}{W_{d}}\right) \times 100
$$

Where $\mathrm{W}_{\mathrm{s}}$ and $\mathrm{W}_{\mathrm{d}}$ are the nanogel weights swollen in the water and in dry state, respectively.

Effect of initial solution pH: Uptake experiments were carried out at different $\mathrm{pH}$ values $(2.0-6.0)$ and $25^{\circ} \mathrm{C}$ by shaking $0.05 \mathrm{~g}$ dry nanogels with $10 \mathrm{ml}(100 \mathrm{mg} / \mathrm{L}) \mathrm{Cu}^{2+}$, for $8 \mathrm{~h}$ at $250 \mathrm{rpm}$ with. The $\mathrm{pH}$ of the solution adjusted using $0.01 \mathrm{~mol} / \mathrm{L} \mathrm{HNO}_{3}$ or $0.01 \mathrm{~mol} / \mathrm{L} \mathrm{NaOH}$ solutions.

Effect of equilibration time: Measurements of $\mathrm{Cu}^{2+}$ uptake using a batch method were adjusted by placing $0.05 \mathrm{~g}$ of PVA/p(AAm-NIPAm) nanogels adsorbent in a flask containing $10 \mathrm{~mL}(100 \mathrm{mg} / \mathrm{L}) \mathrm{Cu}^{2+}$ at $\mathrm{pH}$ 6.0. The contents of these flasks were agitated on a shaker at $250 \mathrm{rpm}$ and $25^{\circ} \mathrm{C}$. Samples were taken at time intervals from 5 to $50 \mathrm{~min}$ for the analysis of residual $\mathrm{Cu}^{2+}$ concentration in solution.

Effect of initial $\mathrm{Cu}^{+2}$ concentration: The effect of initial concentration of the $\mathrm{Cu}^{2+}$ on the uptake were carried out by placing $0.05 \mathrm{~g}$ of dry PVA/p (AAm-NIPAm) nanogels adsorbent in a series of flasks containing $10 \mathrm{~mL}$ of $\mathrm{Cu}^{2+}$ at different concentrations (100-5000 $\mathrm{mg} / \mathrm{L}$ ) and $\mathrm{pH}$ 6.0. The content of the flasks were equilibrated on the shaker at a constant agitation speed $250 \mathrm{rpm}$ for $24 \mathrm{~h}$ after adsorption, the residual concentration of the $\mathrm{Cu}^{2+}$ was determined.

Competitive heavy metal ions adsorption: To survey the 
competitive adsorption performed batch-wise from solutions containing metal ions $\mathrm{Pb}^{2+}$ and $\mathrm{Ni}^{2+}$ between $\mathrm{Cu}^{2+}$, the concentration was $100 \mathrm{mg} / \mathrm{L}$ for each metal. $0.05 \mathrm{~g}$ of PVA/p(AAm-NIPAm) nanogels adsorbent were added into $30 \mathrm{~mL}$ multi metal solution, stirred, and incubated at room temperature with the initial $\mathrm{pH} 6$. After adsorption, the $\mathrm{Cu}^{2+}$ ions concentration in the remaining solution was determined.

Desorption and regeneration experiments: For desorption studies, $0.05 \mathrm{~g}$ of PVA/p(AAm-NIPAm) nanogels adsorbent were loaded with $\mathrm{Cu}^{2+}$ using $10 \mathrm{~mL}(100 \mathrm{mg} / \mathrm{L})$ metal ion solution at $25^{\circ} \mathrm{C}$, $\mathrm{pH} 6.0$ and contact time for $2 \mathrm{hr}$. $\mathrm{Cu}^{2+}$ loaded dry nanogels were collected, and carefully washed with distilled water to remove any un adsorbed $\mathrm{Cu}^{2+}$. The nanogels adsorbents were agitated with $10 \mathrm{~mL}$, $0.1 \mathrm{~mol} / \mathrm{L} \mathrm{HCl}$. To determine their reusability, the desorbed nanogels were regenerated with $0.1 \mathrm{~mol} / \mathrm{L} \mathrm{NaOH}$ for $30 \mathrm{~min}$ and then used for another adsorption. Three consecutive adsorption-desorption cycles were conducted using the same nanogels.

\section{Results and Discussion}

\section{Synthesis and characterization of PVA/p(AAm-NIPAm) nanogels}

PVA/ECH nanogels were synthesized using a suspension crosslinking technique with epichlorohydrin as crosslinking agent in aqueous alkaline conditions. ECH was widely used as a crosslinker to react with the $(-\mathrm{OH})$ groups of the PVA. In alkaline conditions the $(-\mathrm{OH})$ groups of PVA becomes alcoholate anion that attacks the epoxy groups of ECH to form a monoether of chloropropanediol [17]. A new epoxy group will yield by chloride displacement rearranges of the chloropropanediol monoether [18]. In the partial hydrolysis of the amide group, nucleophilic addition of hydroxide to the amide carbonyl followed by elimination of amide ion to afford an acrylic acid residue [19]. The linkage between PVA nanogels and p(AAm-NIPAm) takes place and the amide ion then removes a proton from the acrylic acid residue to form a more stable carboxylate anion and ammonia evolved. A possible mechanism of the polymerization of PVA/p(AAm-NIPAm) is presented in the Scheme 1.

Figure 1, shows the FTIR spectrum of PVA/p (AAm-NIPAm) before

$$
\begin{aligned}
& \text { 1) } \left.\left.\mathrm{n} \mathrm{CH}_{2}=\mathrm{CH}+\mathrm{m} \mathrm{CH}_{2}=\mathrm{CH} \underset{\mathrm{APS}}{-}-\mathrm{CH}_{2}-\mathrm{CH}\right]_{\mathrm{n}}-\mathrm{CH}_{2}-\mathrm{CH}\right]_{\mathrm{m}} \\
& \begin{array}{llll}
\mathrm{CONH}_{2} & \mathrm{CONHCH}\left(\mathrm{CH}_{3}\right)_{2} & \mathrm{CONH}_{2} & \mathrm{CONHCH}\left(\mathrm{CH}_{3}\right)_{2}
\end{array} \\
& \text { Acrylamide } \mathrm{N} \text {-isopropyl acrylamide } \\
& \text { P(AAm-co-NIPAm) hydrogel }
\end{aligned}
$$

$$
\begin{aligned}
& \text { 2) } \mathrm{P}-\mathrm{OH}+\underset{\underset{\mathrm{CONH}}{2}}{\left.-\underset{\mathrm{CONHCH}}{\mathrm{CH}}+\mathrm{CH}_{3}\right)_{2}} \\
& \text { Crosslinked PVA P(AAm-Co-NIPAm) hydrogel } \\
& \text { (P) } \\
& \text { PVA/P(AAm-Co-NIPAm) nanogel }
\end{aligned}
$$

Scheme 1: Synthesis of crosslinked PVA/p(AAm-NIPAm) nanogels.

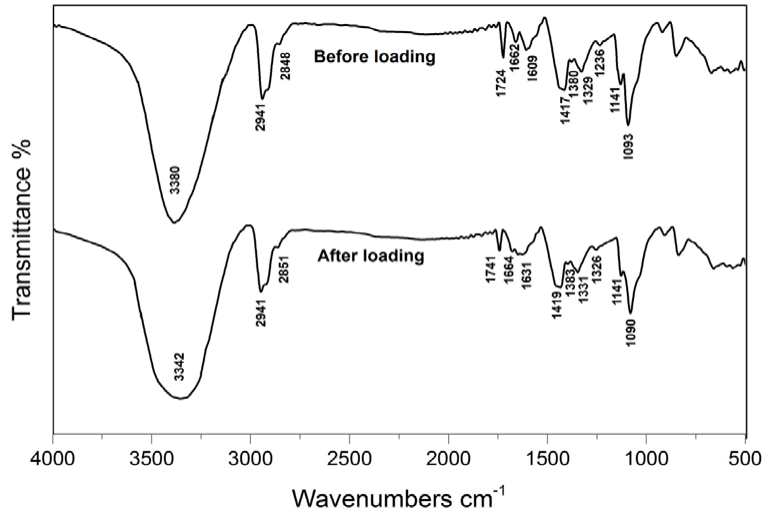

Figure 1: FTIR spectra of PVA/P(0.5AAm-co-0.5NIPAm) (mol:mol\%) nanoge before and after adsorption of $\mathrm{Cu}^{2+}$

and after adsorption of $\mathrm{Cu}^{2+}$. For PVA/p(AAm-NIPAm) nanogels, the chemical structure was identified by formation of absorption band at $1714 \mathrm{~cm}^{-1}$ that belongs to the ester groups between crosslinked PVA nanoparticle and p(AAm-NIPAm) [20], as in the scheme 1. The bands at $1462,1627,2923 \mathrm{~cm}^{-1}$, and $3440 \mathrm{~cm}^{-1}$ are related to the stretching vibration of $\mathrm{COO}^{-}$(symmetric), $\mathrm{COO}^{-}$(asymmetric), aliphatic $-\mathrm{CH}$, and $\mathrm{O}-\mathrm{H}$, respectively [21]. The peak at $1384 \mathrm{~cm}^{-1}$ belongs to stretching vibration of new bond $\mathrm{C}-\mathrm{O}-\mathrm{C}$ stretching vibration from the reacted ECH with PVA. Whereas the band appeared at $1035 \mathrm{~cm}^{-1}$ is characteristic for bending vibration of $\mathrm{OH}$ group. The band at 1627 $\mathrm{Cm}^{-1}$ related to the overlap stretching vibration of carbonyl group from NIPAm as well as the NH bending [22]. The results show that a crosslinking reaction occurs between $\mathrm{ECH}$ and the hydroxyl groups of PVA with the hydrolyzed amide group of AAm which copolymerized with NIPAm.

In the spectra of PVA/P(AAm-co-NIPAm) nanogel loaded with $\mathrm{Cu}^{2+}$ ions, the significant decrease in band intensity and shifting the peaks from 1662 to $1664 \mathrm{~cm}^{-1}$ and from 1609 to $1631 \mathrm{~cm}^{-1}$ after $\mathrm{Cu}^{2+}$ adsorption depict the participation of $\mathrm{N}-\mathrm{H}$ in adsorption process. As the PVA/P(AAm-co-NIPAm) nanogel loaded with $\mathrm{Cu}^{2+}$, the bond energy was altered by the chemical reaction in the adsorption process, which in turn resulted in the decrease and shifted of the spectral intensity for the $1724 \mathrm{~cm}^{-1}$ stretching. This elucidated that $\mathrm{Cu}^{2+}$ had bound with hydrolyzed AAm moieties of the P(AAm-co-NIPAm) [23]. Moreover, decrease the intensity of peak $1141 \mathrm{~cm}^{-1}$ after $\mathrm{Cu}^{2+}$ adsorption refers to $\mathrm{C}-\mathrm{O}$ stretching of carboxyl groups. These support that carboxyl groups of the hydrolyzed AAm moieties are responsible for the $\mathrm{Cu}^{2+}$ adsorption onto the nanogels.

Figure 2, shows TGA thermogram of the PVA/p(AAm-NIPAm-) nanogel. The wt. \% loss of nanogel shows two steps, the nanogel begins to degrade after $100^{\circ} \mathrm{C}$, followed by rapid loss around $250^{\circ} \mathrm{C}$. The weight loss around $250^{\circ} \mathrm{C}$ ( $8.5 \mathrm{wt}$. \%) can emerge from the evaporation of physically absorbed water. It shows that the nanogel has a good thermal stability for adsorption studies.

Figure 3 shows, that the size of nanoparticles plays an important role in determining the possibility of their use for sorption of heavy metals. Figure 3 a shows that the PVA polymer chains form physically crosslinked nanogels ranged from 200 to $500 \mathrm{~nm}$ and form aggregate about $150 \mathrm{~nm}$ in diameter, like a caddice or rope, which may be attributed to the strong hydrogen bonding of PVA inter-chains. These 


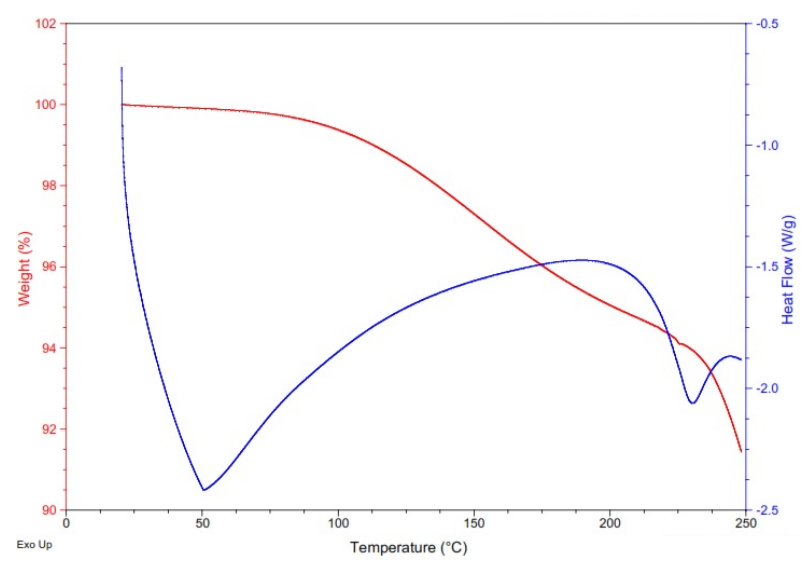

Figure 2: Thermograms of PVA/p(0.5 AAm -0.5 NIPAm) (mol:mol\%) nanogels.
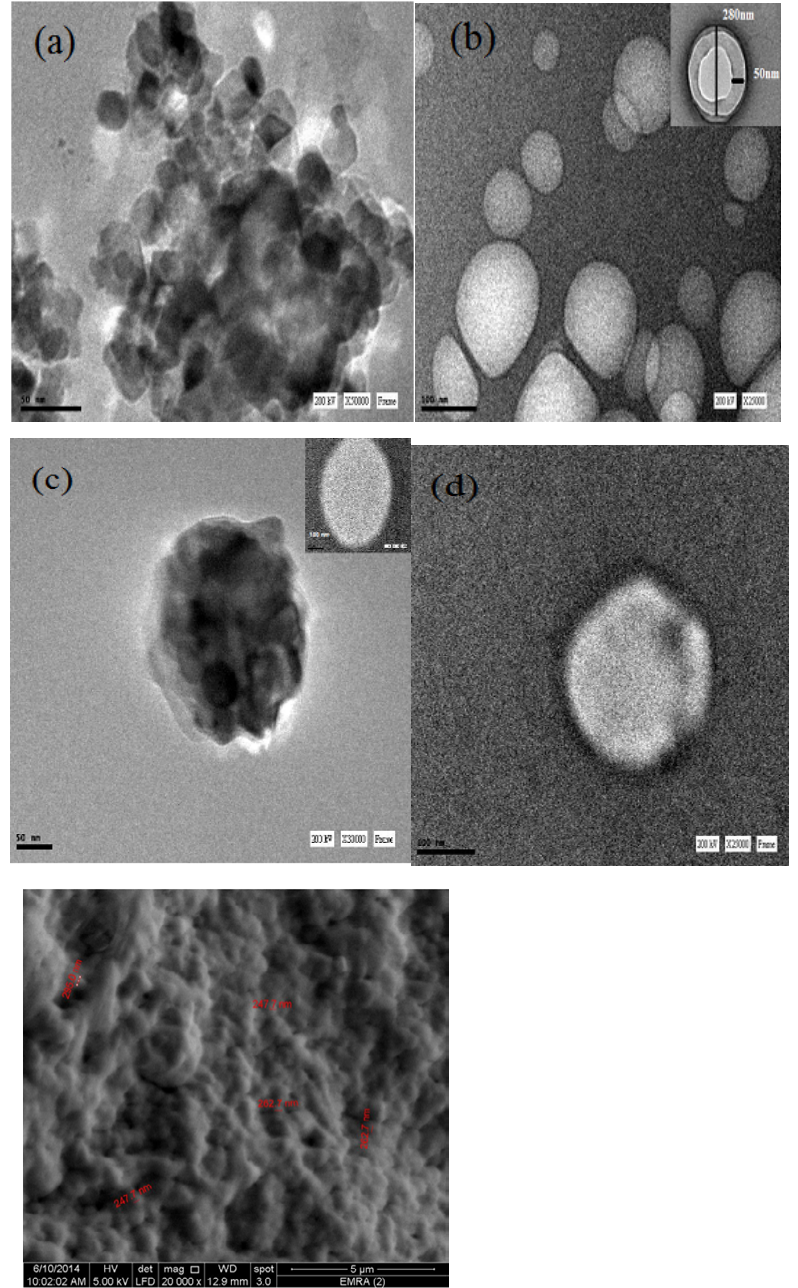

Figure 3: (a-d) TEM photograph of (a)PVA, (b) PVA/P(0.5 AAm-co -0.5 NIPAm) (mol:mol\%), (c) PVA/P(0.1 AAm-co -0.9 NIPAm) (mol:mol\%) and (d) PVA/P(0.9 AAm-co -0.1NIPAm) (mol:mol\%) nanogels. (e) Study the interior morphology of PVA/P(AAm-Co-NIPAm).

PVA particulates seems to be some fragments divided form the PVA "caddice." These results indicate that the PVA configuration in water solution had gotten some changes from its initial coil or aggregate caddice like to unattached particulates with acetone addition and the PVA Nano-particulate or micro-particulate could be formed in a mixed solvent of water and acetone. These particulates formed dispersed spherical nanoparticles when linked with $\mathrm{P}(\mathrm{AAm}-\mathrm{co}$ NIPAm) nanogels with different molar ratio. The PVA nanogel coated with pure $\mathrm{P}(\mathrm{AAm}-c o-\mathrm{NIPAm})$ colloidal hydrogels are spherical in nature and have a relatively narrow size distribution with an average effective diameter of the nanoparticles ranges from 50 to $100 \mathrm{~nm}$, in the absence of surfactant and the crosslinking reaction of the network. Figures 3b-3d, shows the different applied molar ratios from $\mathrm{P}(\mathrm{AAm}-$ co-NIPAm) to the PVA nanoparticle, suggested that there are two different networks in the gel nanoparticle networks. The primary network is crosslinked PVA chains inside each nanoparticle, while the secondary network is a crosslniked system of the nanoparticle PVA/P (AAm-co-NIPAm) themselves. The particle size distribution of PVA/P (AAm-co-NIPAm) nanogel was varied based on P(AAm-co-NIPAm) copolymer compositions. As a result, the nanoparticle network could be used to entrap heavy metal with its primary and secondary structures, respectively. This will enhances the capability of PVA/ $\mathrm{P}$ (AAm-co-NIPAm) nanogel as adsorbent for extraction of pollutants from industrial waste water.

Figure 3e Studies the morphology of PVA/P(AAm-co-NIPAm) (50wt.:50wt. \%) nanoparticles which uniformly smaller agglomerates spherical with a mean diameter around $(250 \pm 35) \mathrm{nm}$ in a dry state. In addition all these particles have similar raspberry like surface morphology. At temperature below the VPTT, the spherical hydrogel networks are solvated by hydrogen bonding between water molecules and the both the amide PNIPAm groups and PAAm moieties of $\mathrm{P}$ (NIPAM-co-AAm) hydrogel shell. Above the VPTT, the P(AAm-coNIPAm) hydrogel particles undergo a volume phase transition from coil to the collapsed globule conformation, as a result of the shrinkage of $\mathrm{P}(\mathrm{AAm}-\mathrm{co}$-NIPAm) hydrogel particles responsible for the less drastic expansion among networks

\section{Swelling behavior of PVA/P(AAm-co-NIPAm) nanogels}

The dependence of the swelling capacity for PVA/p (AAm-NIPAm) nanogels is illustrated in Figure 4. After crosslinking and hydrolysis, with an increase in the AAm concentration the swelling capacity will increase, reaching the maximum value of swelling capacity $1220 \%$. The increase in swelling capacity in the initial stage may be due to the greater availability of monomer molecules in the vicinity of the chain propagating sites of pNIPAm macro radicals [24]. Moreover, higher AAm content enhances the hydrophilicity due to presence of carboxylate ion causes a stronger affinity for more absorption of water. Consequently, overall hydrophilicity of PVA/p(AAm-NIPAm) was improved with higher $(0.9 \mathrm{~mol} \%)$ AAm content and possess more hydrophilic groups within its structure and the swelling ratio may be the highest among the others nanogels, hence their swelling ratios increased.

\section{Adsorption characteristics of $\mathrm{Cu}^{2+}$ ions by PVA/P(AAm-co- NIPAm) nanogels}

Effect of pH: The solution pH is known to be an important variable which affecting the amount of ion adsorption by an adsorbent, it can influence the protonation of functional groups on the adsorbent as well as the heavy metal ions in the solution [25]. Figure 5, clearly shows the effects of initial $\mathrm{pH}(2.0-6.0)$ on the adsorption capacity of $\mathrm{Cu}^{2+}$ for PVA/p(AAm-NIPAm) nanogels. It was evident that the amounts of $\mathrm{Cu}^{2+}$ adsorption mainly depend on $\mathrm{pH}$ values of the adsorption 
Citation: Sarhan AA, Akl MA, Razaq K (2015) Adsorption Characteristics of Copper (II) lons from Aqueous Solution onto lonic Cross-linked Pva/ P(Aam-Nipaam) Core-shell Nanogels. J Nanomedic Nanotechnol S7:001. doi:10.4172/2157-7439.S7-001

Page 5 of 9

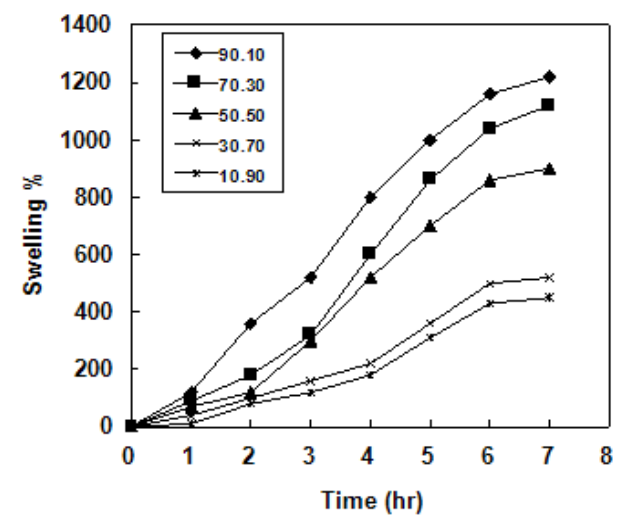

Figure 4: Effect of swelling (\%) as a function of time on PVA/p (AAm-NIPAm) with different composition (Volume $=25 \mathrm{~mL}$, dose $=0.05 \mathrm{~g}$ and $\mathrm{pH}$ 6).

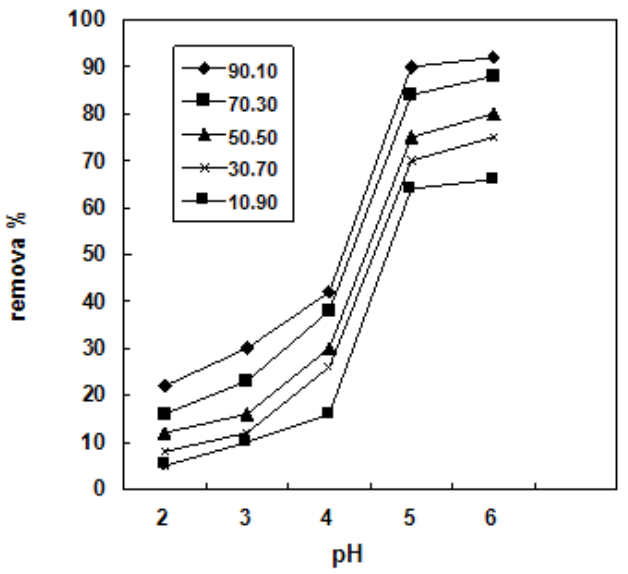

Figure 5: Effect of $\mathrm{pH}$ on $\mathrm{Cu}^{2+}$ adsorption on PVA/p (AAm-NIPAm) (Initial concentration $\mathrm{Cu}^{2+} 100 \mathrm{mg} \mathrm{L}^{-1}$, dose: $0.05 \mathrm{~g}$ and volume $10 \mathrm{~mL}$ ).

medium. The uptake of $\mathrm{Cu}^{2+}$ was found gradual increase from $\mathrm{pH} 2.0-$ 4.0 , beyond which values increase sharply from 4.0 to 5.0 and the highest adsorption $\mathrm{pH}$ value at 6.0; this may be because of the protonation of $-\mathrm{NH}_{2}$ from the acrylamide groups and the corresponding $-\mathrm{OH}$ in the PVA under acidic conditions, generating repulsive charges between these functional groups and $\mathrm{Cu}^{+2}$ ions. The effective $\mathrm{Cu}^{+2}$ extraction when $\mathrm{pH} 6.0$ to reach $66 \mathrm{mg} / \mathrm{g}$ for the higher $(0.9 \mathrm{~mol} \%)$ pNIPAm content than that of $92 \mathrm{mg} / \mathrm{g}$ for the higher ( $0.9 \mathrm{~mol} \%$ ) pAAm content due to the dissociation of amide group is favored at higher $\mathrm{pH}$ values to carboxylate ion and the active sites become increasingly ionized and the $\mathrm{Cu}^{+2}$ ions are more adsorbed due to the carboxyl ions have the stronger electrostatic attraction to the metal ions [26].

Effect of $\mathrm{Cu}^{2+}$ ions concentration: Initial ion concentrations play an important role in determination of the heavy metal ion amount adsorption by an adsorbent. In this study the maximum adsorption of $\mathrm{Cu}^{2+}$ ions on nanogels were measured at different concentrations (100$5000 \mathrm{mg} / \mathrm{l})$. Figure 6 shows that the adsorption of $\mathrm{Cu}^{2+}$ increased almost linearly with the initial ion concentration from 100 to $500 \mathrm{mg} / \mathrm{l}$. When the $\mathrm{C}_{0}$ was $3000 \mathrm{mg} / \mathrm{l}$, the $\mathrm{q}_{\mathrm{e}}$ reached $126 \mathrm{mg} / \mathrm{l}$ for higher $(0.9 \mathrm{~mol} \%)$ pAAm content and $78 \mathrm{mg} / \mathrm{l}$ for higher $(0.9 \mathrm{~mol} \%)$ pNIPAm and this due to the partial hydrolysis of amide group, that lead to formation of $-\mathrm{COO}^{-}$ion which enhances more chelating sites for adsorption, and $\mathrm{q}_{\mathrm{e}}$ much higher than the literature-reported for $\mathrm{Cu}^{2+}$ ion on other adsorbent as in Table 1. This demonstrates that the PVA/p(AAmNIPAm) nanogels adsorbent have an efficient capacity for removing $\mathrm{Cu}^{2+}$ from wastewater.

Adsorption isotherms studies: The equilibrium adsorption isotherm describing the amount of adsorbate adsorbed on adsorbent and the concentration of dissolved adsorbate at equilibrium. The Langmuir and Freundlich isotherm were used and expressed by the following equations (Equations. 4 and 5).

$$
\begin{aligned}
& \frac{C_{e}}{q_{e}}=\frac{1}{k_{L} q_{\max }}+\frac{C_{e}}{q_{\text {max }}} \\
& \ln q_{e}=\ln k_{f}+\frac{1}{n} \ln C_{e}
\end{aligned}
$$

Where $\mathrm{C}_{e}$ is the equilibrium concentration of $\mathrm{Cu}^{+2}(\mathrm{mg} / \mathrm{L})$, qe is the amount of $\mathrm{Cu}^{+2}$ sorbed on the nanogel $(\mathrm{mg} / \mathrm{g}), \mathrm{K}_{\mathrm{L}}$ a constant of the Langmuir model $(\mathrm{mg} / \mathrm{L}), \mathrm{q}_{\max }$ is the maximum amount of $\mathrm{Cu}^{+2}$ that can be sorbed by the PVA/p (AAm-NIPAm) nanogel, $\mathrm{K}_{\mathrm{F}}$ is the Freundlich adsorption constant. The constant $\mathrm{n}$ is the empirical parameter related to the intensity of adsorption which varies with the heterogeneity of the material. When $1 / \mathrm{n}$ values are in the range $0.1<1 / \mathrm{n}<1$, the adsorption process is favorable [34].

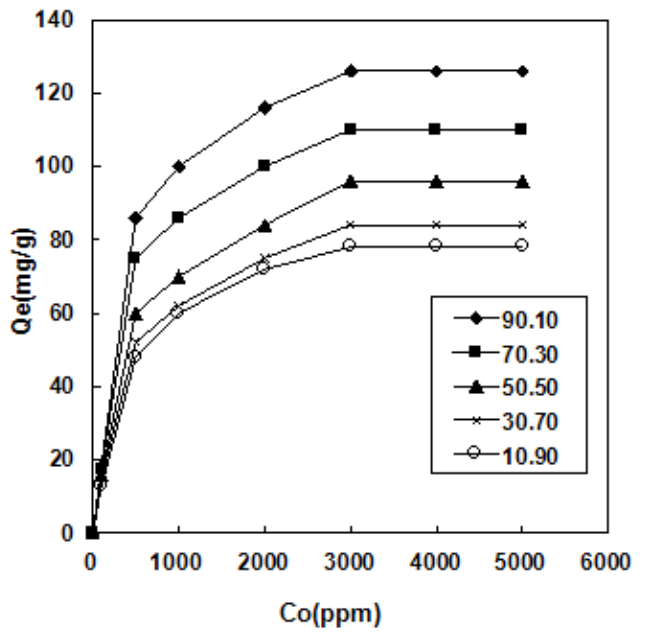

Figure 6: Effect of initial $\mathrm{Cu}^{2+}$ concentration by PVA/p (AAm-NIPAm) nanogels

\begin{tabular}{|c|c|c|}
\hline Adsorbent & $\begin{array}{l}\text { Adsorption capacity for } \\
\qquad \mathrm{Cu}^{2+}(\mathrm{mg} / \mathrm{g})\end{array}$ & References \\
\hline Modified silica aerogel & 90.1 & [27] \\
\hline $\begin{array}{c}\text { Chitosan-coated MNPs modified with } \\
\text { alpha-ketoglutaric acid }\end{array}$ & 96.15 & [28] \\
\hline $\begin{array}{c}\text { Amino functionalized } \mathrm{Fe}_{3} \mathrm{O}_{4} @ \mathrm{SiO}_{2} \\
\text { core-shell NPS }\end{array}$ & 29.85 & [29] \\
\hline $\begin{array}{c}\text { Amphiphilic PMMA/PEI core-shell } \\
\text { nanoparticles }\end{array}$ & 14 & [30] \\
\hline $\begin{array}{l}\text { Crosslinked chitosan with } \\
\text { epichlorohydrin }\end{array}$ & 35.46 & [31] \\
\hline Hydroxyapatite nanoparticles & 36.9 & [32] \\
\hline $\begin{array}{l}\text { Fungal biomass immobilized within a } \\
\text { loofa sponge (FBILS) }\end{array}$ & 98.9 & [33] \\
\hline $\begin{array}{c}\text { PVA/p(AAm-NIPAm) core-shell } \\
\text { nanogels }\end{array}$ & 126 & This work \\
\hline
\end{tabular}
adsorbent on adsorption uptake $\left(\mathrm{q}_{\mathrm{e}}\right)($ Volume $=10 \mathrm{~mL}$, dose $=0.05 \mathrm{~g}$ and $\mathrm{pH}$ 6).

Table 1: Comparison of adsorption capacities for $\mathrm{Cu}^{2+}$ of various adsorbents with PVA/p(AAm-NIPAm) nanogels adsorbent. 
Citation: Sarhan AA, AkI MA, Razaq K (2015) Adsorption Characteristics of Copper (II) lons from Aqueous Solution onto lonic Cross-linked Pva/ P(Aam-Nipaam) Core-shell Nanogels. J Nanomedic Nanotechnol S7:001. doi:10.4172/2157-7439.S7-001

Page 6 of 9

The plot of the experimental $\mathrm{C}_{\mathrm{e}} / \mathrm{q}_{\mathrm{e}}$ against $\mathrm{Ce}$ and $\ln \mathrm{q}_{\mathrm{e}}$ against $\ln \mathrm{C}$ gives the slope of $1 / \mathrm{q}_{\max }$, intercept $1 / \mathrm{K}_{\mathrm{L}} \mathrm{q}_{\max }$ and the values of $1 / \mathrm{n}, \ln \mathrm{K}_{\mathrm{F}}$ are calculated from the slope and intercept of the plot of $\ln \mathrm{q}_{e}$ against $\ln$ $\mathrm{C}_{\mathrm{e}}$, for the experimental data in Figures $7 \mathrm{a}$ and $7 \mathrm{~b}$. Show the Langmuir and Freundlich curves for $\mathrm{Cu}^{+2}$ adsorption on PVA/p(AAm-NIPAm) nanogels adsorbent along with the experimental data.

The values of the Langmuir and freundlich constants and the correlation coefficients are listed in Table 2. Based on the coefficient of determination obtained, it can be concluded that the Freundlich equation gave a better fit, for example 0.9999 for $0.9 \mathrm{~mol} \%$ pAAm to the experimental data than the Langmuir equation, so the Freundlich isotherm correlated better than Langmuir isotherm with the experimental data. The values of $1 / \mathrm{n}$ at equilibrium are between 0.213 to 0.272 shows a favorable adsorption and this would seem to suggest that a physical mechanism, which is referred the adsorption bond becomes weak [35] and conducted with Van der Waals forces rather than chemical adsorption is dominant when it is used for adsorbing $\mathrm{Cu}^{+2}$. One of the Freundlich constants $\mathrm{K}_{\mathrm{F}}$ indicates the

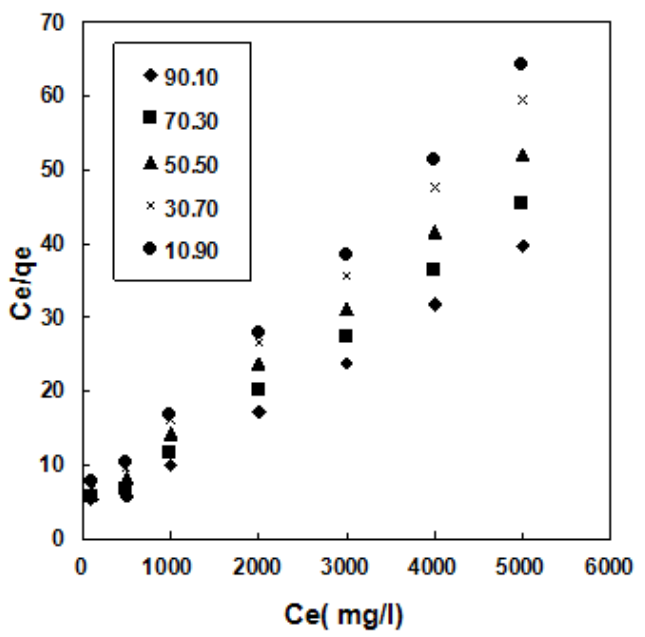

Figure 7a: Langmuir plots for the adsorption of $\mathrm{Cu}^{2+}$ onto PVA/p(AAm-NIPAm) nanogels adsorbent.

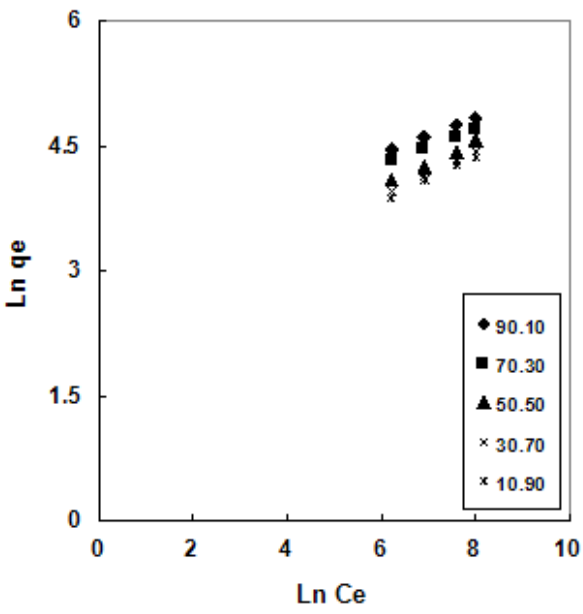

Figure 7b: Freundlich plots for the adsorption of $\mathrm{Cu}^{2+}$ onto PVA/p(AAm-NIPAm) nanogels adsorbent.

\begin{tabular}{|l|c|c|c|c|c|c|}
\hline \multirow{2}{*}{$\begin{array}{l}\text { Adsorbent } \\
\text { (mol.:mol.\%) }\end{array}$} & \multicolumn{3}{|c|}{$\begin{array}{c}\text { Langmuir isotherm } \\
\text { Parameters }\end{array}$} & \multicolumn{2}{c|}{$\begin{array}{c}\text { Freundlich isotherm } \\
\text { parameters }\end{array}$} \\
\cline { 2 - 7 } & $\mathbf{K}_{\mathbf{L}}$ (min $\left.^{-1}\right)$ & $\mathbf{R}_{\mathbf{1}}{ }^{2}$ & $\begin{array}{l}\mathbf{q} \mathbf{m a x} \\
\mathbf{( m g / g )}\end{array}$ & $\begin{array}{c}\mathbf{K}_{\mathbf{F}} \\
(\mathbf{m g} / \mathbf{g})\end{array}$ & $\mathbf{R}_{\mathbf{2}}{ }^{2}$ & $\mathbf{1 / n}$ \\
\hline PVA/p (90NIPAm-10AAm) & 0.00228 & 0.9956 & 138.88 & 1.1405 & 0.9999 & 0.213 \\
\hline PVA/p (70NIPAm-30AAm) & 0.00186 & 0.9970 & 121.95 & 1.0939 & 0.9988 & 0.213 \\
\hline PVA/p (50NIPAm-50AAm) & 0.00204 & 0.9976 & 107.25 & 0.8985 & 0.9941 & 0.260 \\
\hline PVA/p (30NIPAm-70AAm) & 0.00217 & 0.9983 & 93.45 & 0.8249 & 0.9995 & 0.268 \\
\hline PVA/p (10NIPAm-90AAm) & 0.00225 & 0.9979 & 86.20 & 0.7851 & 0.9923 & 0.272 \\
\hline
\end{tabular}

Table 2: Langmuir and Freundlich adsorption isotherm parameters.

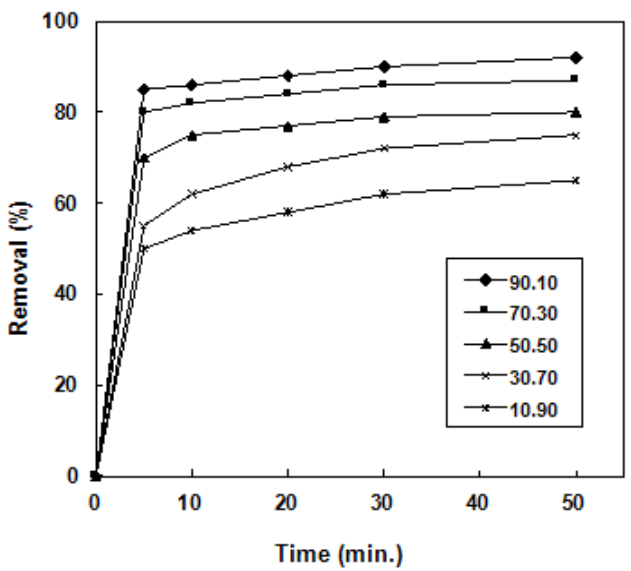

Figure 8: Effect of contact time on the removal of $\mathrm{Cu}^{2+}$ onto PVA/p (AAmNIPAm) nanogels ( $\mathrm{pH} \mathrm{6.0,} \mathrm{dosage} 0.05 \mathrm{~g}$ and time $50 \mathrm{~min}$ ).

adsorption capacity of the adsorbent. The values of $\mathrm{K}_{\mathrm{F}}$ at equilibrium were between 1.1405 and 0.7851 . The magnitude of $\mathrm{K}_{\mathrm{F}}$ values indicates that $\mathrm{p}(0.9 \mathrm{AAm}-0.1 \mathrm{NIPAm}) \mathrm{mol}: \mathrm{mol}(\%)$ possesses higher adsorption affinity towards $\mathrm{Cu}^{2+}$ compared with others. The data reflects that $\mathrm{Cu}^{+2}$ adsorption on the PVA/p(AAm-NIPAm) nanogels can be fitted to the Freundlich isotherm model very well than Langmuir.

Adsorption kinetics: The kinetics of adsorption for the prepared PVA/p(AAm-NIPAm) nanogels is desirable to determine whether the behavior of heavy metal ion adsorption on the adsorbents can be described by a theoretical model that is predictive. Figure 8 , shows the results of the time-dependent $\mathrm{Cu}^{2+}$ adsorption performances of the PVA/p(AAm-NIPAm) nanogels. The adsorption was a very fast process. The amount of adsorption increased rapidly in the first $5 \mathrm{~min}$, contributing to about $85 \%$ of the ultimate adsorption amount, and then augmented slowly and approached the adsorption equilibrium in about $50 \mathrm{~min}$. This type of adsorption behaviors is typical of the specific adsorption process in which adsorption rate is usually dependent upon the number of available adsorption sites on the surface of the adsorbent and eventually controlled by the attachment of the metal ions on the surfaces [36].

The adsorption kinetic models were applied to interpret the experimental data to determine the controlling mechanism of $\mathrm{Cu}^{2+}$ adsorption from aqueous solution. Here, Lagergren pseudo-firstorder, Ho and McKay pseudo-second-order models were used to test dynamical experimental data.

The pseudo-first order kinetic of Lagergren is given by:

$\log \left(q_{e}-q_{t}\right)=\log q_{e}-\frac{k_{1}}{2.303} t$ 
Where $\mathrm{q}_{\mathrm{t}}$ is the amount of $\mathrm{Cu}^{2+}$ adsorbed per unit of adsorbent $(\mathrm{mg} / \mathrm{g})$ at time $\mathrm{t}, \mathrm{K}_{1}$ is the pseudo-first-order rate constant $\left(\mathrm{min}^{-1}\right)$. The adsorption rate constant $\left(\mathrm{K}_{1}\right)$ were calculated from the plot of $\log \left(\mathrm{q}_{\mathrm{e}}{ }^{-}\right.$ qt) against $\mathrm{t}$.

Ho and McKay presented the pseudo-second order kinetic as:

$$
\frac{t}{q_{t}}=\frac{1}{k_{2} q_{e}^{2}}+\frac{t}{q_{e}}
$$

Where $\mathrm{K}_{2}$ is the pseudo-second order rate constant $\left(\mathrm{g} \cdot \mathrm{mg}^{-1} \cdot \mathrm{min}^{-1}\right)$, the values of $K_{2}$ and $q_{e}$ were obtained from the intercept and slope of the plot of $(\mathrm{t} / \mathrm{q})$ versus $t$. These parameters in Figure 9, were calculated and summarized in Table 3.

It can be seen that the correlation coefficients for the pseudofirst-order kinetic model were nearly lower, and that the $\mathrm{q}_{\mathrm{cal}}$ deviated considerably from the $\mathrm{q}_{\text {exp }}$ data, which suggest that this adsorption system is pseudo-second order kinetic adsorption process. This is because in many cases pseudo-first-order equation does not fit well to the whole range of contact time and is generally applicable only over the initial stage of the adsorption process [37]. The coefficients of determination for the pseudo-second-order kinetic model obtained with range 0.999 to 0.997 . The $\mathrm{q}_{\text {cal }}$ data agree very well with the $\mathrm{q}_{\mathrm{exp}}$ data. The results show that the adsorption process of $\mathrm{Cu}^{2+}$ onto PVA/ $\mathrm{p}$ (AAm-NIPAm) nanogels adsorbent followed the pseudo-secondorder model and that the adsorption is probably controlled by the chemical process [38].

Adsorption mechanism: The adsorption mechanism of the adsorbate onto the adsorbent follows three steps. These steps are. (i) Film diffusion, (ii) pore diffusion and (iii) intraparticle transport. Furthermore, the effect of intraparticle diffusion on adsorption rate can

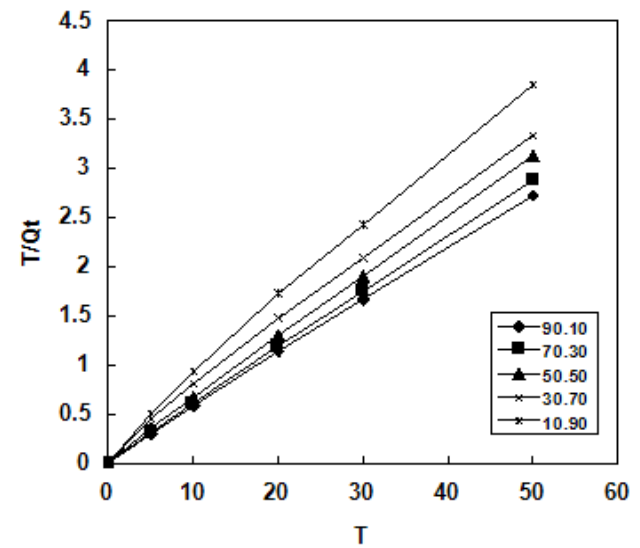

Figure 9: Pseudo-second-order plot of $\mathrm{Cu}^{2+}$ adsorption kinetics on the PVA/p (AAm-NIPAm) nanogels. be calculated based on the relation of adsorption capacity and time, which usually is expressed as follow:

$$
\mathrm{K}_{\mathrm{i}}=\mathrm{q}_{\mathrm{t}} / \mathrm{t}^{0.5}+\mathrm{C}
$$

Where $\mathrm{q}_{\mathrm{t}}$ amount of metal adsorbed at any time $(\mathrm{mg} / \mathrm{g}), \mathrm{K}_{\mathrm{i}}$ : Intraparticle diffusion rate constant $\left(\mathrm{mg} / \mathrm{g} \mathrm{min}^{0.5}\right)$, C: is the intercept of straight lines, which gives information about the boundary layer thickness $[39,40]$. On fitting data to the above equation, if the linear correlation value is close to unity, then intraparticle diffusion process is effective onto nanogels. Figure 10, illustrated the intraparticle diffusion curves for $\mathrm{Cu}^{+2}$ adsorption. As shown in figure, the adsorption process tends to be followed by two phases and the resulting fitting line did not pass the origin [41]. It was found that an initial linear portion ended with a smooth curve followed by another second linear one. The two phases in the intraparticle diffusion plot suggests that the adsorption process takes place by surface adsorption and the intraparticle diffusion. The initial curved portion of the plot was rapid, indicates the boundary layer effect while the second linear portion is due to intraparticle or pore diffusion [39]. On the other hand, the intercept of the plot reflects the boundary layer effect. Larger intercept, the greater is the major contribution of the surface adsorption in the rate limiting step. The intercept and correlation coefficient values of $\mathrm{P}(0.9 \mathrm{~mol} \%)$ AAm possess 16.29 intercept and $\mathrm{R}^{2} 0.991$ closed to unity was greater compared with other nanogels, the calculated intraparticle diffusion coefficient $\mathrm{Ki}$ value at different nanogels are shown in Table 3. As described in adsorption kinetics, the $\mathrm{Cu}^{+2}$ adsorption onto nanogels can be fitted well by the pseudo second order kinetic model. The pseudo second order kinetic model assumed that the chemical reaction mechanisms, which include ion-exchange, adsorption, chemisorption and chelation. The nitrogen and oxygen atoms present in nanogel chain derived from hydrolysis of AAm to carboxylate anions and presence of free oxygen and amide group have lone pairs of electrons that can bind well with $\mathrm{Cu}^{+2}$ through an electron pair sharing to form a stable complex [42,43]. In the present work, $\mathrm{Cu}^{+2}$ may be adsorbed onto nanogels through chelation mechanisms by coordination covalent bonds to the nanogel structure.

Adsorption of competitive ions: The removal of coexisting competitive ion of $\mathrm{Cu}^{2+}, \mathrm{Ni}^{2+}$ and $\mathrm{Pb}^{2+}$ was considered, since the natural and industrial effluents rarely contain a single heavy metal ion, and some of ions in the effluent may be reduce the adsorption of others or may coadsorb along with another ions [25]. The results are shown in Figure 11. The binding capacities of the three metal ions decreased under the competitive conditions since various ions are present in the wastewater and the affinity order of the three metal ions adsorption was $\mathrm{Cu}^{2+}>\mathrm{Ni}^{2+}>\mathrm{Pb}^{2+}$. The ion selectivity observed for $\mathrm{Cu}^{2+}$ was higher especially for higher $0.9 \mathrm{~mol} \%$ pAAm content and this might be attributed to the smaller ionic radius of $\mathrm{Cu}^{2+}$ ions $(0.71 \AA \AA$ ) than other metal ions, affinity of Coordination (formation of inner sphere complexes) with the carboxylic acid groups [44], or may also be due to

\begin{tabular}{|c|c|c|c|c|c|c|c|c|c|}
\hline Adsorbent & & do-first-c & & & Pseudo & 1-orde & & Intra-par & liffusion \\
\hline (mol.:mol.\%) & $\mathrm{K}_{1}\left(\min ^{-1}\right)$ & $\mathbf{R}_{1}{ }^{2}$ & $q_{\text {cal }}(\mathrm{mg} / \mathrm{g})$ & $\mathrm{K}_{2}(\mathrm{mg} / \mathrm{g})$ & $\mathbf{R}_{2}^{2}$ & $\mathbf{q}_{\text {cal. }}$ & $\mathbf{q}_{\text {exp. }}$ & $K_{\text {id }}$ & $\mathbf{R}^{2}$ \\
\hline PVA/P (90AAm-10NIPAm) & 0.0151 & 0.9948 & 1.6 & 0.109 & 0.9996 & 18.4 & 18.4 & 0.3001 & 0.9968 \\
\hline PVAIP (70AAm-30NIPAm) & 0.0328 & 0.9684 & 2.1 & 0.146 & 0.9998 & 17.4 & 17.4 & 0.2954 & 0.9811 \\
\hline PVAIP (50AAm-50NIPAm) & 0.0375 & 0.9742 & 2.8 & 0.112 & 0.9997 & 16.1 & 16 & 0.3885 & 0.9324 \\
\hline PVA/P (30AAm-70NIPAm) & 0.0322 & 0.9956 & 5.7 & 0.042 & 0.9974 & 15.2 & 15 & 0.8183 & 0.9705 \\
\hline PVA/P (10AAm-90NIPAm) & 0.0271 & 0.9805 & 4.2 & 0.051 & 0.9971 & 13.1 & 13 & 0.6266 & 0.9904 \\
\hline
\end{tabular}
the Jahn-Teller effect which is mastery for copper complexes $[45,46]$

Table 3: Kinetic parameters for $\mathrm{Cu}^{2+}$ ions onto PVA/P (AAm-co-NIPAm) nanogels adsorbent. 


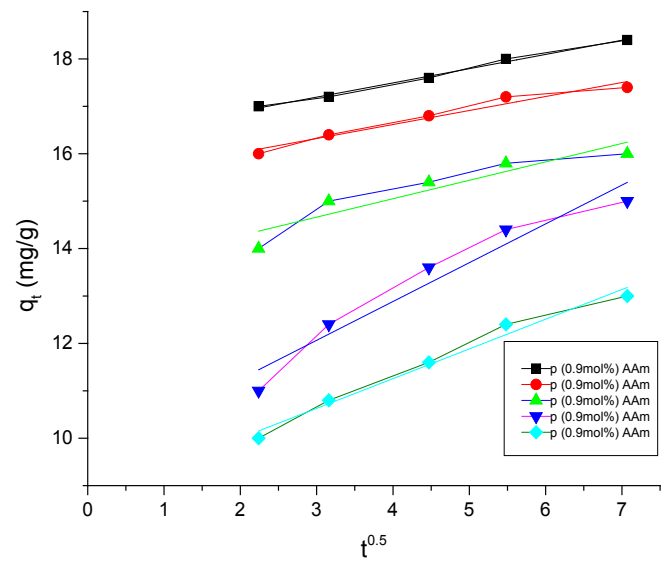

Figure 10: Intraparticle diffusion kinetics of $\mathrm{Cu}^{2+}$ adsorption onto nanogels.

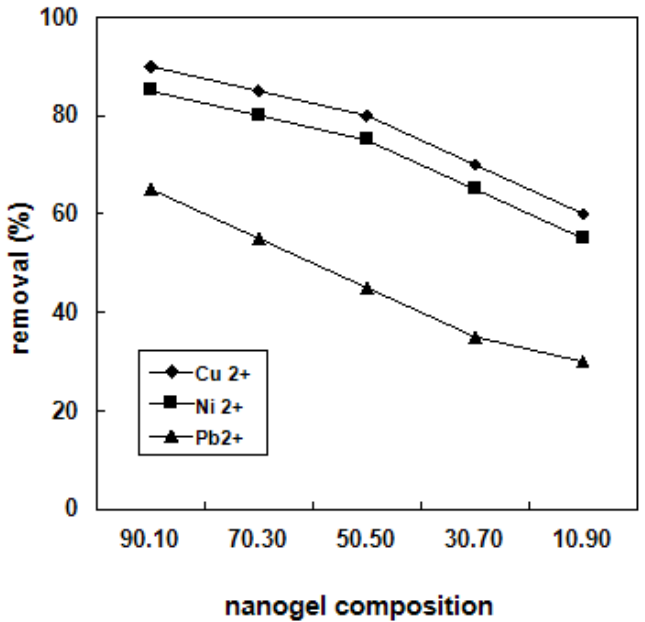

Figure 11: Competitive adsorption of $\mathrm{Cu}^{2+}, \mathrm{Ni}^{2+}$ and $\mathrm{Pb}^{2+}$ ontoPVA/p (AAmNIPAm) nanogels adsorbent.

Desorption and reusability: The results showed that all the nanogels showed over $97 \%$ desorption ratio efficiently at equilibrium, under acidic conditions the interaction between hydrolyzed pAAm and $\mathrm{Cu}^{2+}$ easily weaken and subsequently $\mathrm{Cu}^{2+}$ ions are released from the adsorbent into the desorbing medium with $0.1 \mathrm{~mol} / \mathrm{l} \mathrm{HCl}$ as the eluent. Figure 11, by consecutive adsorption-desorption cycles the adsorption capacity depends on the nanogels composition. The result indicates that over $96 \%$ desorption ratio in the first adsorption-desorption cycle decreased with decreasing of mol\% AAm to reach $90.9 \%$ desorption ratio for $0.1 \mathrm{~mol} \% \mathrm{AAm}$, more over the amount of $\mathrm{Cu}^{2+}$ adsorption decreased after regeneration. Nevertheless, they maintained nearly 92.3\% for 0.9 mol AAm from the original adsorption capacity after three cycles of adsorption-desorption, which indicates that the PVA/ $\mathrm{p}$ (AAm-NIPAm) nanogels were excellent reusability and well suited for the design of a continuous sorption process (Figure 12).

\section{Conclusion}

(1) Synthesis of different molar ratio of PVA/p (AAm-NIPAm) nanogels were synthesized successfully and characterized by FTIR,TGA and TEM, the TEM presented in this study showed the PVA core dispersed well in p(NIPAm-AAm) through chemical crosslinking

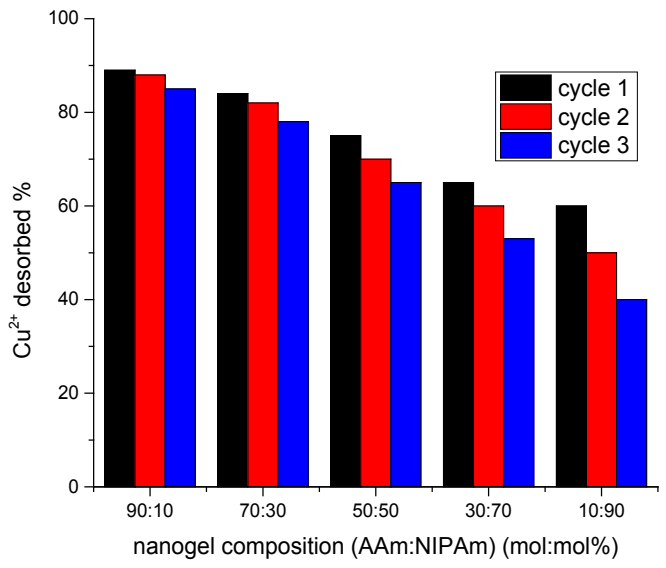

Figure 12: Effect of adsorption-desorption cycles on adsorption capacity.

and core shell structure produced.

(2) Various factors affecting the uptake behavior such as monomer concentration, $\mathrm{pH}$, initial concentration, contact time, competitive adsorption and regeneration study was evaluated. The maximum adsorption of $\mathrm{Cu}^{2+}$ ions $126 \mathrm{mg} / \mathrm{g}$.

(3) pAAm considered higher adsorption uptake because hydrolysis of acrylamide into carboxylate ion groups along the polymer which chelates well with $\mathrm{Cu}^{2+}$ in the solution rather than pNIPAm.

(4) Kinetic models of pseudo-first-order, pseudo- second-order were applied to the experimental data. The adsorption was found to follow the pseudo-second-order model.

(5) Isotherm models of PVA/p (NIPAm-AAm) nanogels adsorbent for $\mathrm{Cu}^{2+}$ matches with Freundlich isotherm.

(6) PVA/p(NIPAm-AAm) nanogels adsorbent selective for $\mathrm{Cu}^{2+}$ with $\mathrm{Pb}^{2+}$ and $\mathrm{Ni}^{2+}$ and could be desorbed more than $95 \%$ by $0.1 \mathrm{~mol}$ $\mathrm{L}^{-1} \mathrm{HCl}$ solute and reuse again.

\section{References}

1. Nriagu JO, Pacyna JM (1988) Quantitative assessment of worldwide contamination of air, water and soils by trace metals. Nature 333: 134-139.

2. Liu C, Bai R, San Ly Q (2008) Selective removal of copper and lead ions by diethylenetriamine-functionalized adsorbent: behaviors and mechanisms. Water Res 42: 1511-1522.

3. Ozay O, Ekici S, Baran Y, Aktas N, Sahiner N (2009) Removal of toxic metal ions with magnetic hydrogels. Water Res 43: 4403-4411.

4. Hu S, Fürst P, Hamer D (1990) The DNA and Cu binding functions of ACE1 are interdigitated within a single domain. New Biol 2: 544-555.

5. Aaseth J, Norseth T (1986) Copper. In: Handbook on the Toxicology of Metals (L. Friberg, G.F. Nordberg, V.B. Vouk, eds). Amsterdam: Elsevier 2: 233-254.

6. Tisato F, Marzano C, Porchia M, Pellei M, Santini C (2010) Copper in diseases and treatments, and copper-based anticancer strategies. Med Res Rev 30 708-749.

7. Rao GP, Lu C, Su F (2007) Sorption of divalent metal ions from aqueous solution by carbon nanotubes: A review. Sep Purif Technol 58: 224-231.

8. Ho YS, McKay G (2003) Sorption of dyes and copper ions onto biosorbents. Process Biochem 38: 1047-1061.

9. Lee WF, Yuan WY (2000) Thermoreversible hydrogels X: Synthesis and swelling behavior of the ( $\mathrm{N}$-isopropylacrylamide-co-sodium 2-acrylamido-2methylpropyl sulfonate) copolymeric hydrogels. J Appl Polym Sci 77: 17601768. 
Citation: Sarhan AA, AkI MA, Razaq K (2015) Adsorption Characteristics of Copper (II) lons from Aqueous Solution onto lonic Cross-linked Pva/ P(Aam-Nipaam) Core-shell Nanogels. J Nanomedic Nanotechnol S7:001. doi:10.4172/2157-7439.S7-001

10. Esalah JO, Weber ME, Vera JH (2000) Removal of lead from aqueous solutions by precipitation with sodium di-(n-octyl) phosphinate. Sep Purif Technol 18: 25-36.

11. DeMerlis CC, Schoneker DR (2003) Review of the oral toxicity of polyviny alcohol (PVA). Food Chem Toxicol 41: 319-326.

12. Shantora V, Huang RYM (1981) Separation of liquid mixtures by using polymer membranes. III. Grafted poly (vinyl alcohol) membranes in vacuum permeation and dialysis. J Appl Polym Sci 26: 3223-3243.

13. Koyama K, Nishi T, Hashida I, Nishimura M (1982) The rejection of polar organic solutes in aqueous solution by an interpolymer anionic composite reverse osmosis membrane. J Appl Polym Sci 27: 2845-2855.

14. Hong PD, Chou CM, He CH (2001) Solvent effects on aggregation behavior of polyvinyl alcohol solutions. Polymer 42: 6105-6112.

15. Hirokawa Y, Tanaka T (1984) Volume phase transition in a nonionic gel. J Chem Phys 81: 6379-6380.

16. Çaykara T, Domup D (2004) Effects of Temperature and Surfactants on the Equilibrium Swelling Behavior of Poly[acrylamide-co-(itaconic acid)] Hydrogels. Macro Materials and Eng 289: 548-551.

17. Chang C, Duan B, Zhang L (2010) Superabsorbent hydrogels based on cellulose for smart swelling and controllable delivery. Eur Polym J 46: 92-100.

18. Miguel ID, Rieumajou V, Betbeder D (1999) New methods to determine the extent of reaction of epichlorohydrin with maltodextrins. Carbohydrate Res 319 : $17-23$.

19. Caulfield MJ, Qiao GG, Solomon DH (2002) Some aspects of the properties and degradation of polyacrylamides. Chem Rev 102: 3067-3084.

20. Tadokoro $\mathrm{H}$ (1959) Infrared studies of polyvinyl alcohol by deuteration of its $\mathrm{OH}$ groups. Bull Chem Soc Japan 32: 1252-1257.

21. Cuba-Chiem LT, Huynh L, Ralston J, Beattie DA (2008) In situ particle film ATR FTIR spectroscopy of carboxymethyl cellulose adsorption on talc: binding mechanism, pH effects, and adsorption kinetics. Langmuir 24: 8036-8044.

22. Owens DE, Jian Y, Fang JE, Slaughter BV, Chen YH (2007) Thermally responsive swelling properties of polyacrylamide/poly (acrylic acid) interpenetrating polymer network nanoparticles. Macromol 40: 7306-7310.

23. Sun S, Hu J, Tang H, Wu P (2011) Spectral interpretation of thermally irreversible recovery of poly(N-isopropylacrylamide-co-acrylic acid) hydrogel. Phys Chem Chem Phys 13: 5061-5067.

24. Pourjavadi A, Mahdavinia GR (2006) Super absorbency, pH-Sensitivity and Swelling Kinetics of Partially Hydrolyzed Chitosan-g-poly (Acrylamide) Hydrogels. Turk J Chem 30: 595-608.

25. Zhou Y, Zhang L, Fu S, Zheng L, Zhan H (2012) Adsorption behavior of $\mathrm{Cd}^{2+}, \mathrm{Pb}^{2+}$, and $\mathrm{Ni}^{2+}$ from aqueous solutions on cellulose-based hydrogels. BioResources 7: 2752-2765.

26. Zhao L, Mitomo H (2008) Adsorption of heavy metal ions from aqueous solution onto chitosan entrapped CM-cellulose hydrogels synthesized by irradiation. J App Poly Sci 110: 1388-1395

27. Pouretedal HR, Kazemi M (2012) Characterization of modified silica aeroge using sodium silicate precursor and its application as adsorbent of $\mathrm{Cu}^{2+}, \mathrm{Cd}^{2+}$, and $\mathrm{Pb}^{2+}$ ions. Int $\mathrm{J}$ Ind Chem 3: 20-28.

28. Zhou YT, Nie HL, Branford-White C, He ZY, Zhu LM (2009) Removal of Cu+2 from aqueous solution by chitosan-coated magnetic nanoparticles modified with @a-ketoglutaric acid. J Colloid and Interface Sci 330: 29-37.

29. Wang J, Zheng S, Shao Y, Liu J, Xu Z, et al. (2010) Amino-functionalized $\mathrm{Fe}_{3} \mathrm{O}_{4} @ \mathrm{SiO}_{2}$ core-shell magnetic nanomaterial as a novel adsorbent for aqueous heavy metals removal. J Colloid Interface Sci 349: 293-299.

30. Wu AH, Jia J, Luan SJ (2011) Amphiphilic PMMA/PEI core-shell nanoparticles as polymeric adsorbents to remove heavy metal pollutants. Colloids and Surfaces A: Phys Eng Aspects 384: 180-185.
31. Chen AH, Liu SC, Chen CY, Chen CY (2008) Comparative adsorption of $\mathrm{Cu}(\mathrm{II})$ $\mathrm{Zn}(\mathrm{II})$, and $\mathrm{Pb}(\mathrm{II})$ ions in aqueous solution on the crosslinked chitosan with epichlorohydrin. J Hazard Mater 154: 184-191.

32. Wang YJ, Chen JH, Cui YX, Wang SQ, Zhou DM (2009) Effects of lowmolecular-weight organic acids on $\mathrm{Cu}(\mathrm{II})$ adsorption onto hydroxyapatite nanoparticles. J Hazard Mater 162: 1135-1140.

33. Iqbal M, Edyvean RGJ (2004) Biosorption of lead, copper and zinc in a loofa sponge immobilised biomass of Phanerochaete chrysosporium. Min Eng Int 17: 217-223.

34. Vázquez I, Rodríguez-Iglesias J, Marañón E, Castrillón L, Alvarez M (2007) Removal of residual phenols from coke wastewater by adsorption. J Hazard Mater 147: 395-400.

35. Jiang JQ, Cooper C, Ouki S (2002) "Comparison of modified montmorillonite adsorbents, Part I: Preparation, characterization and phenol adsorption." Chemosphere 47: 711-716.

36. Li N, Bai RB (2005) A Novel Amine-shielded Surface Crosslinking of Chitosan Hydrogel Beads for Enhanced Metal Adsorption Performance. Ind Eng Chem Res 44: 6692-6700.

37. Ho YS, McKay G (1999) The sorption of Lead (II) on peat. Water Res 33: 578584

38. Wu YJ, Zhang LJ, Gao CL, Ma JY, Ma XH (2009) Adsorption of Copper lons and Methylene Blue in a Single and Binary System on Wheat Straw. J Chem Eng Data 54: 3229-3234.

39. Atia AA, Donia AM, Yousif AM (2008) Removal of some hazardous heavy metals from aqueous solution using magnetic chelating resin with iminodiacetate functionality. Sep Purif Technol 61: 348-357.

40. Guibal E, Milot C, Tobin JM (1998) Metal-anion sorption by chitosan beats: equilibrium and kinetic studies. Ind Eng Chem Res 37: 1454-1463.

41. Gonga JL, Wanga XY, Zenga GM, Chena L, Denga JH (2012) Copper (II) removal by pectin-iron oxide magnetic nanocomposite adsorbent. Chemical Engineering Journal 185-186: 100-107.

42. Gregor HP, Luttinger LB, Loebl E (1955) Metal-Polyelectrolyte Complexes. I. The Polyacrylic Acid-Copper Complex. J Phys Chem 59: 34-39.

43. Mun GA, Nurkeeva ZS, Khutoryanskiy VV, Sarybayeva GS, Dubolazov AV (2003) pH-effects in the complex formation of polymers I. Interaction of poly(acrylic acid) with poly(acrylamide). Eur Polym J 39: 1687-1691.

44. Mandal R, Sekaly ALR, Hassan NM, Murimboh J, Chakrabarti CL (1999) Effect of the competition of copper and cobalt on the lability of nickel (II)-organic ligand complexes, Part II: in freshwaters (Rideau River surface waters). Anal Chim Acta 395: 323-334.

45. Baba Y, Masaaki K, Kawano Y (1998) Synthesis of a chitosan derivative recognizing planar metal ion and its selective adsorption equilibria of copper(II) over iron(III). React Funct Polym 36: 167-172.

46. Monier M, Abdel-Latif DA (2012) Preparation of cross-linked magnetic chitosan-phenylthiourea resin for adsorption of $\mathrm{Hg}(\mathrm{II}), \mathrm{Cd}(\mathrm{II})$ and $\mathrm{Zn}(\mathrm{II})$ ions from aqueous solutions. J Hazard Mater 209-210: 240-249. 